\title{
An investigation on the fresh and hardened properties of self-compacting concrete incorporating magnetic water with various pozzolanic materials
}

\author{
Majid Gholhaki $^{a}$, Ali Kheyroddin $^{a}$, Mohammad Hajforoush $^{a}$ and Mostafa Kazemi ${ }^{b}$ \\ ${ }^{a}$ Department of Civil Engineering, Semnan University, Postal Code: 35131-19111, Semnan, Iran \\ ${ }^{\mathrm{b}}$ Department of Civil Engineering, University of Guilan, Rasht, Iran
}

Corresponding Author: Majid Gholhaki

E-mail: $\underline{\text { mgholhaki@ semnan.ac.ir }}$

Tel: +989122874869

\begin{abstract}
The main objective of this study was to assess engineering properties of self-compacting concrete (SCC) incorporating magnetic water and silica fume, metakaolin, rice husk ash and fly ash (10\% and $20 \%$ by weight of cement). The fresh properties were investigated by means of slump flow, $\mathrm{T}_{50}$, V-funnel, L-box and visual stability index(VSI). At hardened state, compressive strength was evaluated at the ages of 7 and 28 days and mixes were cast to assess the 28-day splitting tensile strength development and also durability characteristics of concrete were tested for water absorption test at the age of 28 days. Results indicate that magnetic water and pozzolanic materials in SCC can improve the self-compatibility criteria in terms of flowability and viscosity. Furthermore, SCC mixture containing magnetic water and $20 \%$ of silica fume can be considered as an optimum mix design at the age of 28 days where compressive strength and splitting tensile strength increased up to $49 \%$ and $41 \%$, respectively and the value of water absorption decreased up to $55 \%$. Moreover, magnetic water can reduce the amount of high range water reducer (HRWR), required for SCC, up to $45 \%$.
\end{abstract}

Keywords: Self-compacting concrete, Magnetic water, Pozzolanic materials, Fresh and hardened properties. 


\section{Introduction}

Self-compacting concrete (SCC) is a highly fluid concrete which can be replaced easily in complex stirrup and rebar configuration by means of its own weight. This manner can help filling into every corner of a formwork without needing vibrator. In addition, although it is associated with higher cost due to using higher chemical admixtures, it can lead to durability enhancement of structure and reduced time for pouring concrete. SCC was first proposed by Okomorain in 1986 and the prototype of SCC was subsequently developed in 1988 at the University of Tokyo [1]. Later on, to achieve higher durable concrete, SCC has been commonly used throughout the world.

The quality of water, used into the mixer, marks a big impression on engineering properties of concrete. Also, water after passing through a magnetic field of certain strength which is called magnetic water can contribute to repulsion of cement particles from each other that causes to produce hydration layers surrounding these particles [2]. Following that, this procedure is the leading cause of avoiding accumulation of cement particles and improving flowability of concrete, the reason of which is that water can easily pass through these particles. One of the advantages of concrete mixed with magnetic water is that it requires $5 \%$ less cement compared to concrete samples incorporating tap water, and also it can somewhat prevent concrete from freezing [3,4]. A study by Afshin et al.[5] surveyed mechanical properties of high strength concrete by magnetic water technology. They revealed that compressive strength and slump increased by $18 \%$ and $45 \%$, respectively. 
Pozzolanic materials play a key role in producing higher durable and performance concrete and have a good compatibility with environmental protection [6,7]. Some pozzolanic materials such as fly ash (FA), limestone powder, ground blast-furnace slag and silica fume (SF) efficiently enhanced strength properties of SCC [8,9]. Furthermore, Jalal et al. [10] observed that SCC, prepared by SF, increased electrical resistivity, while it led to a decrease in absorbed water in the concrete sample and penetrating chloride ion into longer depth. They also revealed that addition of micro and nanosilica materials improved the consistency of the high performance SCC and reduced the probability of bleeding and segregation where nanoparticles in SCC mixes enhanced compressive and splitting tensile strengths. Meanwhile, they reported that addition of micro and nanosilica materials could contribute to improvement of mechanical, durability and microstructual properties of high performance SCC mixes. Also, the reduction of absorbed water from $4.5 \%$ to $2.76 \%$ and $2.57 \%$ were observed by Sabet et al. [11] for SCC mixes containing $10 \%$ and $20 \%$ SF, respectively, where they showed that replacing $10 \%$ and $20 \%$ of cement by SF resulted in an increase in the compressive strength, at the age of 28 days, to 75.5 and $79.5 \mathrm{MPa}$. They also reported that incorporation of SF increased the high range water reducer (HRWR) demand for 0.6 and 1.1 (\% binder) for the SCC mixes. Generally, in another study, Jalal et al. [12] mentioned that the addition of SF improved the pore structure of concrete and it could act as a filler to enhance the density of concrete, which led to the porosity of concrete reduced remarkably. Experimental results of Leung et al. [13] indicated that when FA alone was 
added in SCC mixes, the reduction in water absorption was lower than using both FA and SF.

This demonstrated that the effect of SF was much higher than that of FA. Furthermore, they concluded that when only FA was used to partially replace ordinary portland cement, the reduction in sorptivity was remarkable when the amount of FA was more than $20 \%$ replacement of ordinary portland cement. The results, obtained by Jalal et al. [14], demonstrated that FA in SCC could improve flowability of concrete and also SCC containing FA had the similar trend in terms of absorbed water and penetrating chloride ion into longer depth as SF did mentioned previously. They also reported that FA addition could lead to general enhancement of compressive strength of SCC mixes at the age of 90 days, while it did not affect the results of splitting tensile strength of SCC. Zhao et al. [15] in an experimental study on SCC incorporating FA and ground granulated blast-furnace slag showed that with the inclusion of FA, ground granulated blast-furnace slag enhanced the initial slump flow and reduced the slump flow loss rate, wet density of the SCC and prolonged the setting times of cement paste. By increasing the replacement level of FA, ground granulated blast-furnace slag led to a higher blocking ratio and segregation ratio of the SCC, which they remained in target range value for each test. Utilizing FA, ground granulated blast-furnace slag in the SCC had not obvious negatively affect the flowability and stability of the fresh SCC. According to the results obtained by Poon et al. [16], although concrete prepared by inclusion of metakaolin (MK) had the same strength of concrete containing SF at the age of 28 days, pozzolanic properties of MK led to higher strength of 
concrete at early ages and filling pores of cement paste better in comparision to other fillers such as SF and FA. As surveyed by Hassan et al. [17], replacing cement by MK raised plastic viscosity of SCC mixes, while there were no changes in SCC incorporating SF in terms of plastic viscosity. They reported that replacing $25 \%$ of cement by MK resulted in an increase in the amount of HRWR by about 30\%. However, the incorporation of MK caused less need for HRWR compared to the addition of SF at the same level of cement replacement. They also concluded that with the inclusion of $8 \% \mathrm{MK}$, SCC could be successfully produced with higher compressive strength by about $14 \%$. However, raising the amount of MK from $8 \%$ to $25 \%$ only improved the compressive strength up to $7 \%$. In addition, incorporation of $\mathrm{MK}$ in SCC mixes could lead to higher freezing resistance and lower penetration of chloride ion into longer depth. As indicated by Dadsetan and Bai [18], MK in SCC mixes led to higher amount of C-S-H gel in presence of higher water/binder (W/B) ratio without affecting the mechanical properties. Furthermore, MK had a greater effect on the microstructural strength of the transition zone than ground granulated blast-furnace slag. Concerning rice husk ash (RHA), as shown by Madandoust et al. [19], albeit pozzolanic reaction of RHA was low at early ages of concrete, there existed a remarkable increase in strength of concrete after 270 days. They also reported that the differences between the uniformity of the properties of RHA concrete and the corresponding control mix indicated a strength variation across the depth of concrete beams following the general pattern of a reasonably uniform distribution from top to bottom, with the top region being of lower strength than the bottom region. The magnitude of this 
variation varied according to the concrete type, with least variation for RHA concrete. The results, obtained by Le and Ludwing [20], demonstrated that the addition of RHA in SCC mixes caused less need for HRWR and it decreased slightly filling and passing abilities and increased remarkably plastic viscosity and segregation resistance of SCC mixes. The incorporation of RHA also avoided from the bleeding of SCC mixes.

Apart from what mentioned previously, a limited number of studies have been conducted by researchers on the effects of magnetic water on SCC mixes containig pozzolanic materials, while magnetic water associated with pozzolanic materials contents can improve engineering properties of concrete mixes. As displayed by Singh and Naval [2] magnetic water could affect engineerng properties of SCC mixes incorporating FA, SF and MK as binary and ternary cementatious material where the highest level of compressive strength was attained up to $47.8 \mathrm{MPa}$ at the age of 28 days for SCC mixes incorporating $70 \%$ ordinary portland cement, 20\% FA and 10\% MK. Another study, performed by Su et al. [21,22], demnstrated that the use of magnetic water could improve compressive strength of concrete incorporating FA or granulated blast-furnace slag up to $10-20 \%$ over control mix and decreased bleeding of concrete. They also reported that the greatest increase in compressive strength of concrete was attained when the magnetic strength of water was of 0.8 and 1.2 Tesla. Meanwhile, Bharath et al. [23] indicated that the use of magnetized water enhanced the workability of concrete mixed with copper slag up to $50 \%$. In addition, recent studies, conducted by Ghods [24] on the effect of magnetic water on the mechanical properties of SCC incorporating 
nanosilica, demonstrated that the compressive and tensile strengths of SCC mixes can be improved at early ages more. According to these studies, it seems that pozzolanic materials can affect performance of magnetic water in SCC mixes. For further investigation, this paper aims to present the results of SCC prepared by inclusion of magnetic water of 0.8 Tesla and SF, MK, RHA and FA(10\% and $20 \%$ by weight of cement) with the W/B ratio of 0.37 . The assessments of fresh properties have been performed by slump flow, required time of SCC to reach $500 \mathrm{~mm}$ length slump-flow diameter $\left(\mathrm{T}_{50}\right)$, V-funnel, L-box and visual stability index(VSI). At hardened state, compressive strength was evaluated at the ages of 7 and 28 days, and mixes were cast to assess the 28-day splitting tensile strength development and also durability characteristics of concrete were tested for water absorption test at the age of 28 days.

\section{Experimental plan}

\subsection{Materials}

Type II Portland cement with a specific density of $3.15 \mathrm{~g} / \mathrm{cm}^{3}$ has been used in this study. SF, MK, RHA and FA with 2.32, 2.6, 2.09 and $2.5 \mathrm{~g} / \mathrm{cm}^{3}$ densities were used to evaluate the flowability of the mixes. The chemical compositions of cement, SF, MK, RHA and FA are indicated in Table 1. Also, the particle size distribution curves of these pozzolanic materials and cement are shown in Fig. 1 where the lowest and highest particle sizes of pozzolanic materials were obtained for SF and RHA. The coarse aggregate with a specific density of $2.66 \mathrm{~g} / \mathrm{cm}^{3}$ was crushed gravel with a nominal maximum size of $19 \mathrm{~mm}$. Meanwhile, natural 
river sand was used as fine aggregate with a specific density of $2.6 \mathrm{~g} / \mathrm{cm}^{3}$. The values of water absorption of coarse and fine aggregate were $1.1 \%$ and $2.25 \%$, respectively. Mixing water used for mixes was magnetic water of 0.8 Tesla as compared to the SCC produced with tap water. According to EFNARC [25], HRWR based on carboxylate was used with density of $1.15 \mathrm{~g} / \mathrm{cm}^{3}$ on the basis of ASTM C494 [26].

Table 1. Chemical composition of Portland cement and pozzolanic materials

\begin{tabular}{cccccc}
\hline $\mathrm{XRF}$ & Cement & SF & MK & RHA & FA \\
\hline $\mathrm{SiO}_{2}$ & 22.45 & 95.23 & 54.5 & 91.26 & 60.1 \\
$\mathrm{Al}_{2} \mathrm{O}_{3}$ & 4.85 & 1.21 & 34.63 & 0.94 & 24.6 \\
$\mathrm{Fe}_{2} \mathrm{O}_{3}$ & 3.95 & 0.91 & 1.42 & 0.37 & 5.1 \\
$\mathrm{CaO}$ & 64.86 & 0.63 & 0.28 & 2.15 & 7.61 \\
$\mathrm{MgO}$ & 0.8 & 0.98 & 0.3 & 0.88 & 0.74 \\
$\mathrm{SO}$ & 0.85 & 0.82 & 0.22 & - & 0.1 \\
$\mathrm{~K}_{2} \mathrm{O}$ & 0.51 & 1.03 & 0.34 & 0.98 & - \\
$\mathrm{Na}_{2} \mathrm{O}$ & 0.25 & 0.31 & 0.1 & 0.46 & 3.23 \\
\hline
\end{tabular}

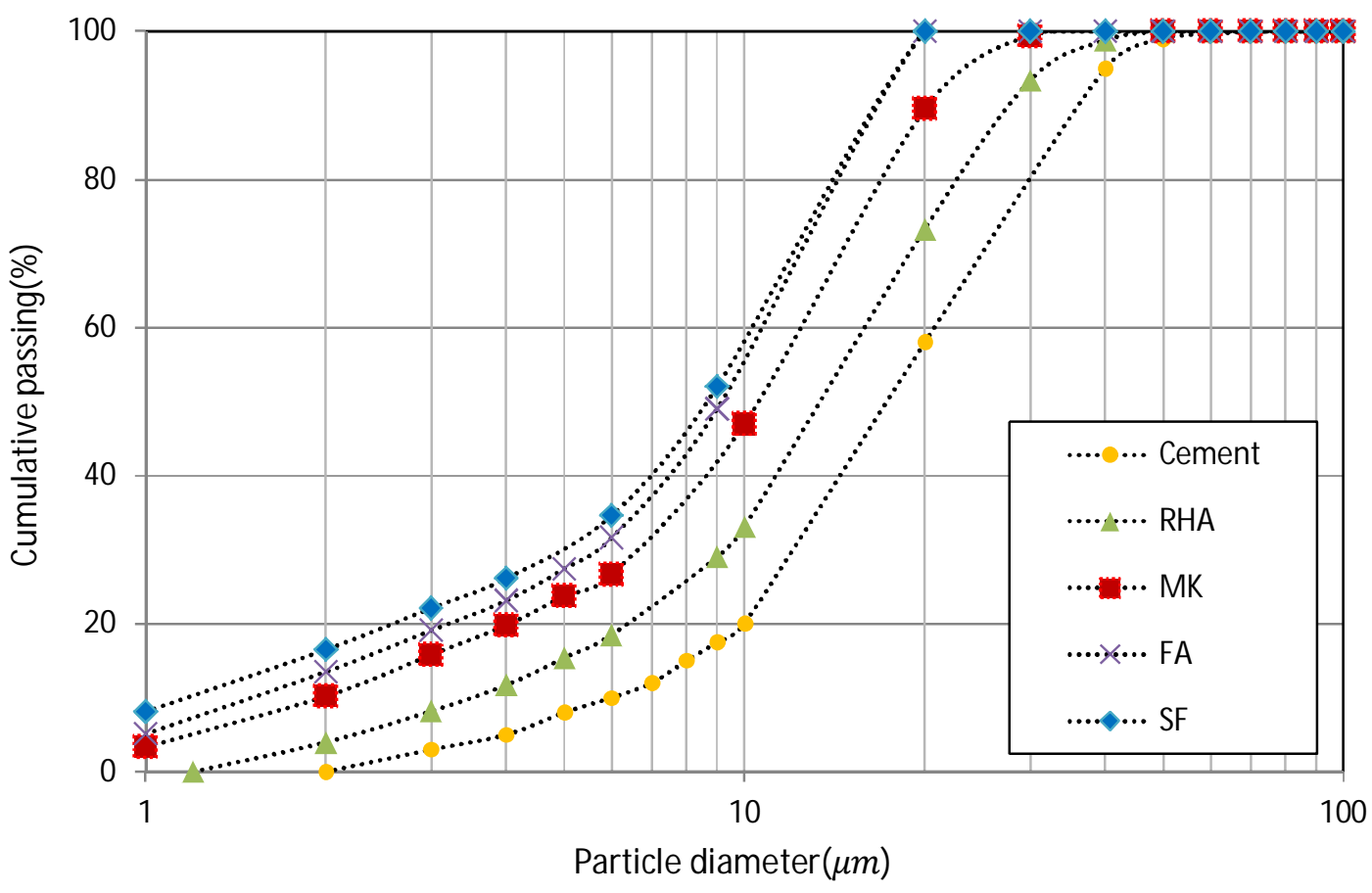

Fig. 1. Particle size distribution curves of cement and pozzolanic materials. 


\subsection{Mixture proportion and test procedure}

To achieve the goals of this study, ten SCC mixes were produced with the W/B ratio of 0.37 . The total weight of cementitious materials was $400 \mathrm{~kg} / \mathrm{m}^{3}$. Two of the ten SCC mixes were prepared by inclusion of magnetic and tap water as control mixes. Eight of them were mixed with magnetic water and contained SF, MK, RHA and FA which were replaced $10 \%$ and $20 \%$ by weight of the total cementitious materials as detailed in Table 2.

For mix preparation, first, natural coarse and fine aggregates were homogenized for $30 \mathrm{~s}$ at normal mixing speed. Then, adding about half of the mixing water into the mixer while mixing goes on for $1 \mathrm{~min}$. Later on, the mixture was rested for $1 \mathrm{~min}$ so that the aggregates could absorb. Thereafter, cement and fillers were added and mixed for one more minute. Finally, the remaining water and HRWR were introduced to the mixture, while mixing was going on for $3 \mathrm{~min}$. This procedure established by Khayat et al. [27] was used to produce SCC. Based on ASTM C496 [28], 15 x $30 \mathrm{~cm}$ cylindrical specimens were casted so as to estimate 28-day splitting tensile strength and $15 \mathrm{~cm}$ cubes were made to be tested by compression testing machine after 7 and 28 days with respect to ASTM C39 [29]. Cubic specimens were also used for absorption test at 28-day with accordance to ASTM C642 [30].

All specimens have been taken out after $24 \mathrm{~h}$ and kept under water curing regime until the testing day. 
Table 2. Mix details $\left(\mathrm{kg} / \mathrm{m}^{\mathbf{3}}\right)$

\begin{tabular}{ccccccccccc}
\hline $\begin{array}{c}\text { Mix. } \\
\text { NO. }\end{array}$ & Mix. ID. & Cement & SF & MK & RHA & FA & Water & $\begin{array}{c}\text { Coarse } \\
\text { aggregate }\end{array}$ & $\begin{array}{c}\text { Fine } \\
\text { aggregate }\end{array}$ & HRWR \\
\hline 1 & CTRL(NW) & 400 & - & - & - & - & 148 & 778 & 1085 & 5.75 \\
2 & CTRL(MW) & 400 & - & - & - & - & 148 & 778 & 1085 & 3.15 \\
3 & SF10 & 360 & 40 & - & - & - & 148 & 766 & 1069 & 3.45 \\
4 & SF20 & 320 & 80 & - & - & - & 148 & 761 & 1062 & 5.37 \\
5 & MK10 & 360 & - & 40 & - & - & 148 & 768 & 1071 & 4.03 \\
6 & MK20 & 320 & - & 80 & - & - & 148 & 765 & 1067 & 6.71 \\
7 & RHA10 & 360 & - & - & 40 & - & 148 & 764 & 1066 & 4.60 \\
8 & RHA20 & 320 & - & - & 80 & - & 148 & 757 & 1056 & 7.48 \\
9 & FA10 & 360 & - & - & - & 40 & 148 & 767 & 1070 & 2.68 \\
10 & FA20 & 320 & - & - & - & 80 & 148 & 764 & 1065 & 2.11 \\
\hline
\end{tabular}

\section{Results and discussions}

\subsection{Fresh concrete results}

In the present study, fresh SCC mixed with magnetic water and SF, MK, RHA and FA was examined by slump flow, $\mathrm{T}_{50}, \mathrm{~V}$-funnel, L-box and VSI. The rheological properties of fresh mixes had a good compatibility with the EFNARC [25] recommendations.

\subsubsection{Slump flow}

The effects of SF, MK, RHA and FA inclusion on the slump flow values are given in Fig.

2. For all mixes, by keeping the amount of HRWR between 2.11 and $7.48 \mathrm{~kg} / \mathrm{m}^{3}$, slump flow was ranging from 670 to $710 \mathrm{~mm}$. The use of magnetic water caused a decrease in HRWR up to $45 \%$ and also an increase in slump flow up to $3 \%$, compared to SCC control mix made with tap water. It can be due to penetrating magnetic water molecules through the hydration layer more easily compared to tap water. In addition, as reported by Singh and Naval [2], magnetic water can contribute to repulsion of cement particles from each other that causes to 
produce hydration layers surrounding these particles. This matter can lead to requiring lower HRWR. As shown in Fig. 2, with the inclusion of 10 and 20\% SF, the amount of HRWR was risen up from 3.45 to $5.37 \mathrm{~kg} / \mathrm{m}^{3}$, while the slump flow was declined from 680 to $670 \mathrm{~mm}$. Generally, the use of SF caused more need for HRWR compared to SCC control mix made with magnetic water to maintain slump flow in a desired range substantially. Higher specific surface of SF may cause these results, which can lead to absorbing HRWR more and declining flowability of mixture, whereas the inclusion of $20 \%$ MK resulted in better flowability and an increase in HRWR up to $20 \%$, compared to SCC incorporating SF. Concernig this, Safiuddin et al.[31] reported that the improvement of flowability of SCC mixes may be due to the liquefying and dispersing actions of the HRWR. In liquefying action, the HRWR increases the flowability by reducing yielding stress and plastic viscosity. These results were also achieved by Madandoust and Mousavi [32]. In addition, Singh and Naval [2] concluded that the addition of MK caused to enhance the workability of SCC mixes higher than FA and SF. Regarding this, as shown in Fig. 2, the slump flow of SCC mixes incorporating $20 \%$ MK was obtained higher than that of SCC mixes containing 20\% FA or $20 \%$ SF. On the other hand, the use of RHA caused more need for HRWR to maintain slump flow in a desired range substantially where the highest dosage of HRWR was used for SCC containing $20 \%$ RHA which was $237 \%$ more than that for SCC control mix made with magnetic water. As mentioned by Zhang and Malhotra [33], the RHA particles are angular and cellular with a honey-comb microstructure which can lead to an increase in interlocking 
characteristics. Safiuddin et al. [31] demonstrated that this manner increased friction among particles which can contribute to higher plastic viscosity. That's why the incorporation of RHA caused more need for HRWR in SCC mixes. Although the use of FA caused more need for HRWR in limited number of mixes with accordance to results obtained by Jalal et al. [14], spherical shape of FA could reduce friction between aggregates and cement paste. Concequently, as given in Fig. 2, the demand for HRWR decreased.

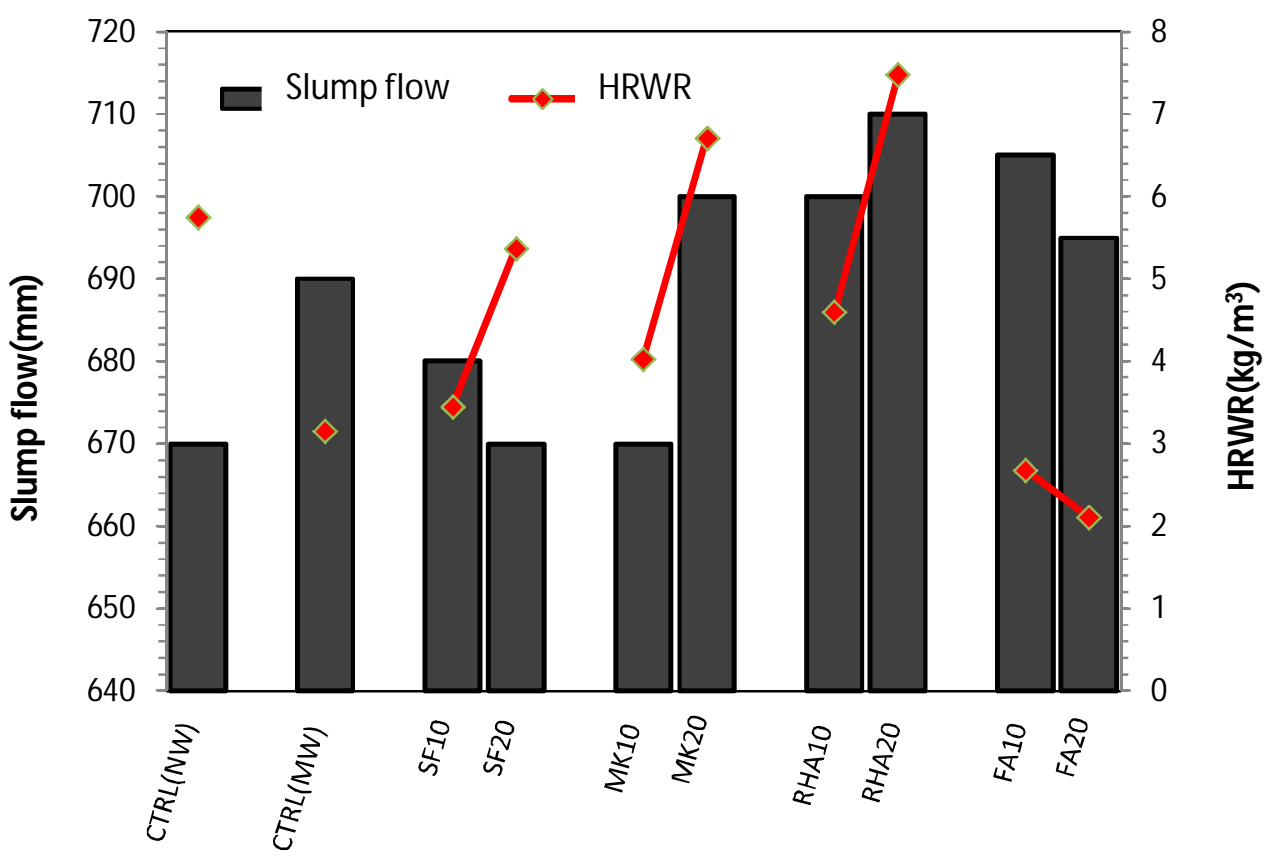

Fig. 2. The effect of pozzolanic materials on the slump flow.

\subsection{2. $T_{50}$ flow time and V-funneltime}

As presented in Fig. 3, the range of $\mathrm{T}_{50}$ flow time is from 2.85 to $5 \mathrm{~s}$. Concerning this, Singh and Naval [2] conducted experimental studies on SCC incorporating magnetic water and FA, SF and MK as binary and ternary cementatious material where $\mathrm{T}_{50}$ flow time was in the range of 4.5-5.5 s. This range nearly was obtained in present study. A large quantity of 
pozzolanic materials in terms of water absorption caused higher plastic viscosity and lower flowability. That's why $\mathrm{T}_{50}$ is more for SCC incorporating different replacement levels of pozzolanic materials, except FA. On the other hand, as shown in Fig. 4, the trends of results obtained by $\mathrm{V}$-funnel are similar to those by $\mathrm{T}_{50}$ flow time for all mixes. As indicated in Figs. 3 and 4, regarding mixes containing pozzolanic materials and magnetic water, by decreasing flow time, viscosity of SCC mixes increased, whereas the reverse was true in the absence of pozzolanic materials in SCC. Also, this manner was seen by Hassan et al. [17] for SCC with the inclusion of MK. Furthermore, in Fig. 5, a regression equation has been proposed where $\mathrm{T}$ and $\mathrm{VF}$ are flow time in $\mathrm{T}_{50}$ and $\mathrm{V}$-funnel, respectively, and also there exists a good correlation between these two tests. Such good correlation implies that either $\mathrm{T}_{50}$ slump flow or V-funnel flow test is adequate to assess the relative viscosity and cohesiveness of SCC. Furthermore, it is noteworthy that lower $\mathrm{V}$-funnel of $\mathrm{T}_{50}$ times may reduce the acceptability of mixture for self compactibility. As shown in Figs. 3 and 4, $\mathrm{T}_{50}$ flow time was obtained between 2.85-5 s and V-funnel time limited between 9-25 s, that all of these flow times satisfied restricted values with accordance to EFNARC [25]. 


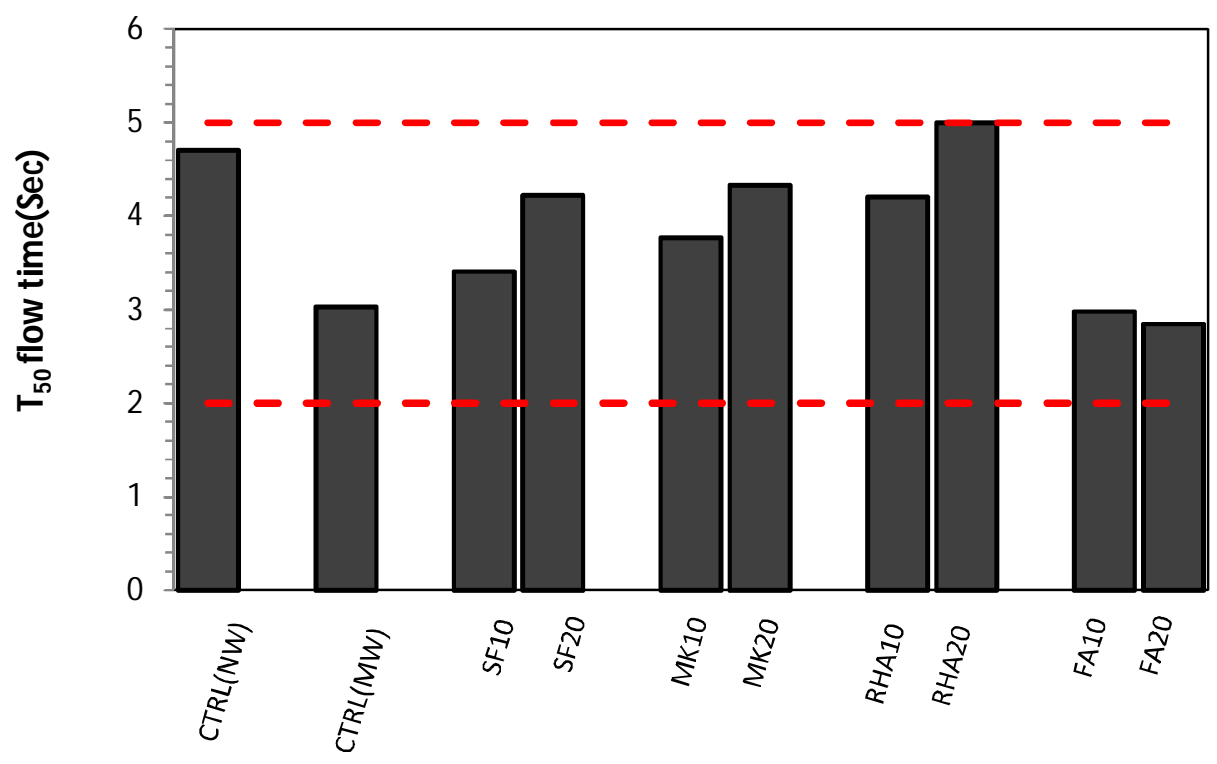

Fig. 3. The effect of pozzolanic materials on the $T_{50}$ flow time.

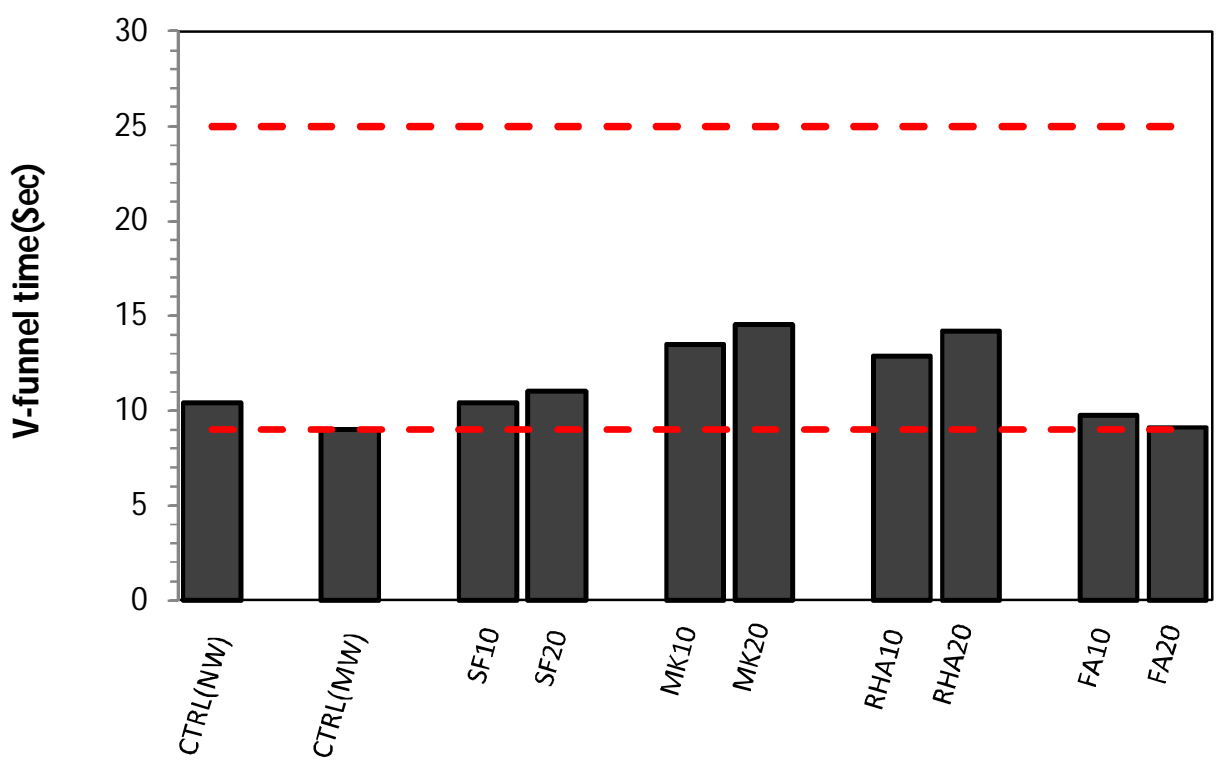

Fig. 4. The effect of pozzolanic materials on the V-funnel time. 


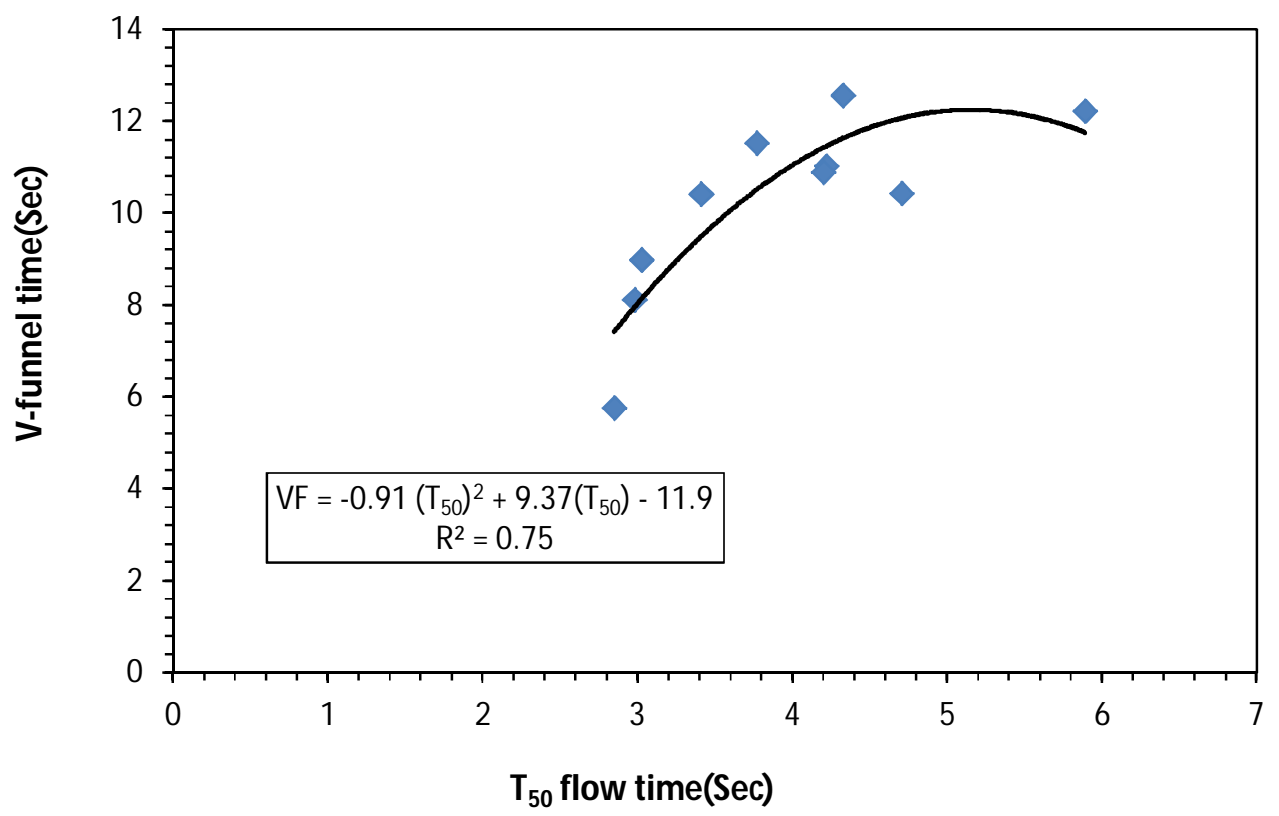

Fig. 5. Variation of viscosity classes with $\mathrm{T}_{50}$ and $\mathrm{V}$-funnel flow times.

\subsubsection{L-boxtest}

As given in Fig. 6, the L-box blocking ratio of SCC with the inclusion of pozzolanic materials changed from 0.8 to 0.91 . According to EFNARC [25], the L-box blocking ratio should be over 0.8 for SCC which has been displayed in Fig. 6. SCC control mix made with magnetic water had better passing ability than SCC control mix made with tap water where blocking ratio of SCC control mix made with magnetic water was obtained $8 \%$ more than that of SCC control mix made with tap water. This value was obtained more than $12 \%$ for SCC incorporating $20 \%$ FA. 


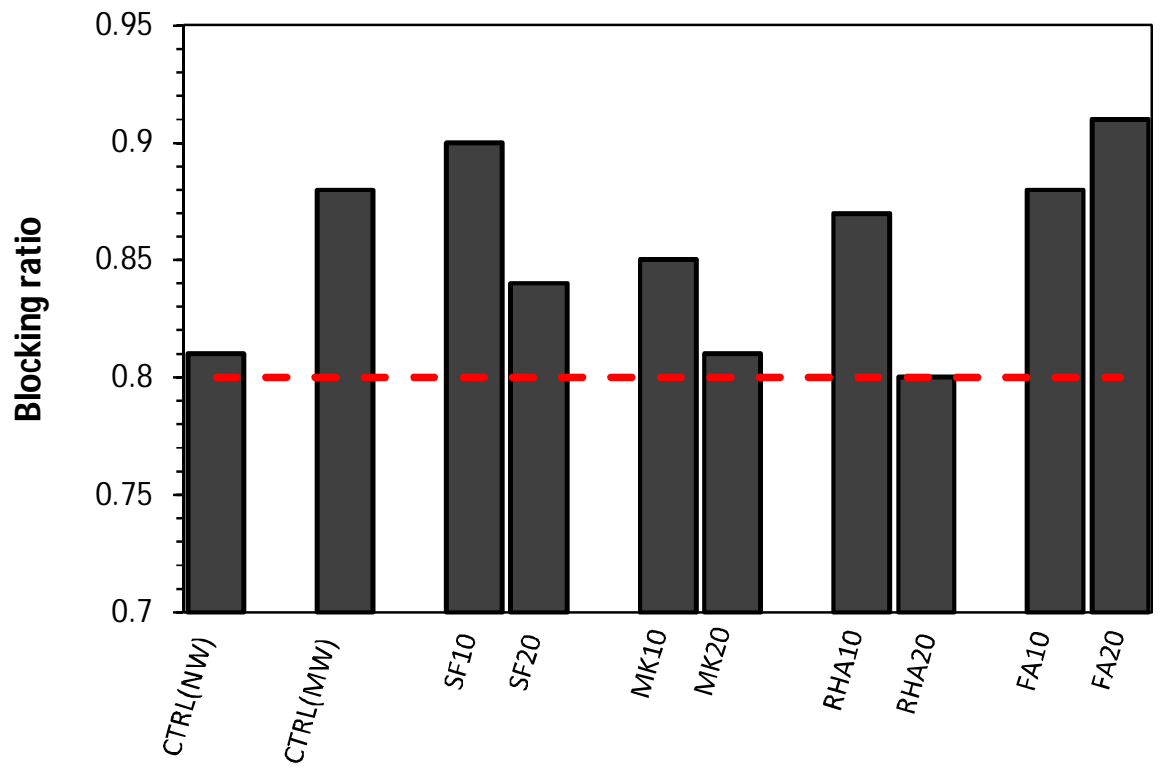

Fig. 6. Blocking ratio of SCC mixes.

\subsection{4. visual stability index (VSI)}

As detected during the slump flow test, there was a good satisfaction with the resistance to bleeding and coarse aggregates segregation which were distributed uniformly in the broken split tensile test specimens. Meanwhile, VSI ranging of 0-1 was achieved for all mixes according to EFNARC [25].

\subsection{Hardened concrete results}

\subsubsection{Compressive strength}

The compressive strength of mixes made with magnetic water and containing $10 \%$ and $20 \%$ SF, MK, RHA and FA were studied and resulted in the ages of 7 and 28 days (Figs. 7 and 8) where compressive strength for SCC mixes with magnetic water and containing $20 \%$ SF, FA, MK and RHA, at the age of 28 days, increased up to $49 \%, 33 \%, 26 \%$ and $1 \%$ 
compared with SCC control mix made with tap water. As presented in Figs. 7 and 8, the enhancement of compressive strength of SCC incorporating magnetic water and pozzolanic materials varied from 30.5 to $40 \mathrm{MPa}$ at the age of 7 days, while the 28-day compressive strength of these mixes was in range of 38.5-57 MPa. Apart from the replacement levels, SF, MK and FA except RHA caused an increase in compressive strength of SCC mixes. The highest 28-day compressive strength was obtained for SCC containing 20\% SF (57 MPa) which can due to higher pozzolanic reactions compared to other mixes at the age of 28 days, as reported by sabet et al. [11]. By contrast, the lowest level of compressive strength at 28 days was obtained for SCC made with 20\% RHA (38.5 MPa). Meanwhile, the compressive strength at 7 days for the same mixture was equal to $30.6 \mathrm{MPa}$. It can be concluded that pozzolanic properties of RHA cannot effeciently react at early ages. FA at $10 \%$ and $20 \%$ replacement levels could enhanced compressive strength of control mix from $36 \mathrm{MPa}$ to 39 and $40 \mathrm{MPa}$, respectively, at the age of 7 days where compressive strength of SCC containnig FA was just a bit more than that of SCC containing SF. Meanwhile, FA in SCC mixes resulted in higher compressive strength compared to SCC containig MK or RHA. The reason is that incorporation of FA is smaller than MK and RHA and it can fill voids of cement paste better [11]. Similar results were obtained by Singh and Naval [2] for replacing cement by $20 \%$ FA in SCC mixes where they investigated the effect of magnetic water on the engineering properties of SCC mixes containing binary and ternary blends. According to this study, the highest level of compressive strength at 28 days was obtained for SCC mixes 
incorporating $70 \%$ ordinary portland cement, $20 \%$ FA and $10 \%$ MK. They concluded that MK reacts rapidly with the excess calcium hydroxide resulting from ordinary portland cement hydration by a pozzolanic reaction, to produce calcium silicate hydrate and calcium aluminosilicate hydrates. Therefore, MK increased compressive Strength for SCC mixes containing binary and ternary blends. In present study, this manner also obtained for SCC mixes incorporating $10 \%$ and $20 \%$ MK where compressive strength was attained up to 46.5 and $48 \mathrm{MPa}$, respectively, at the age of 28 days.

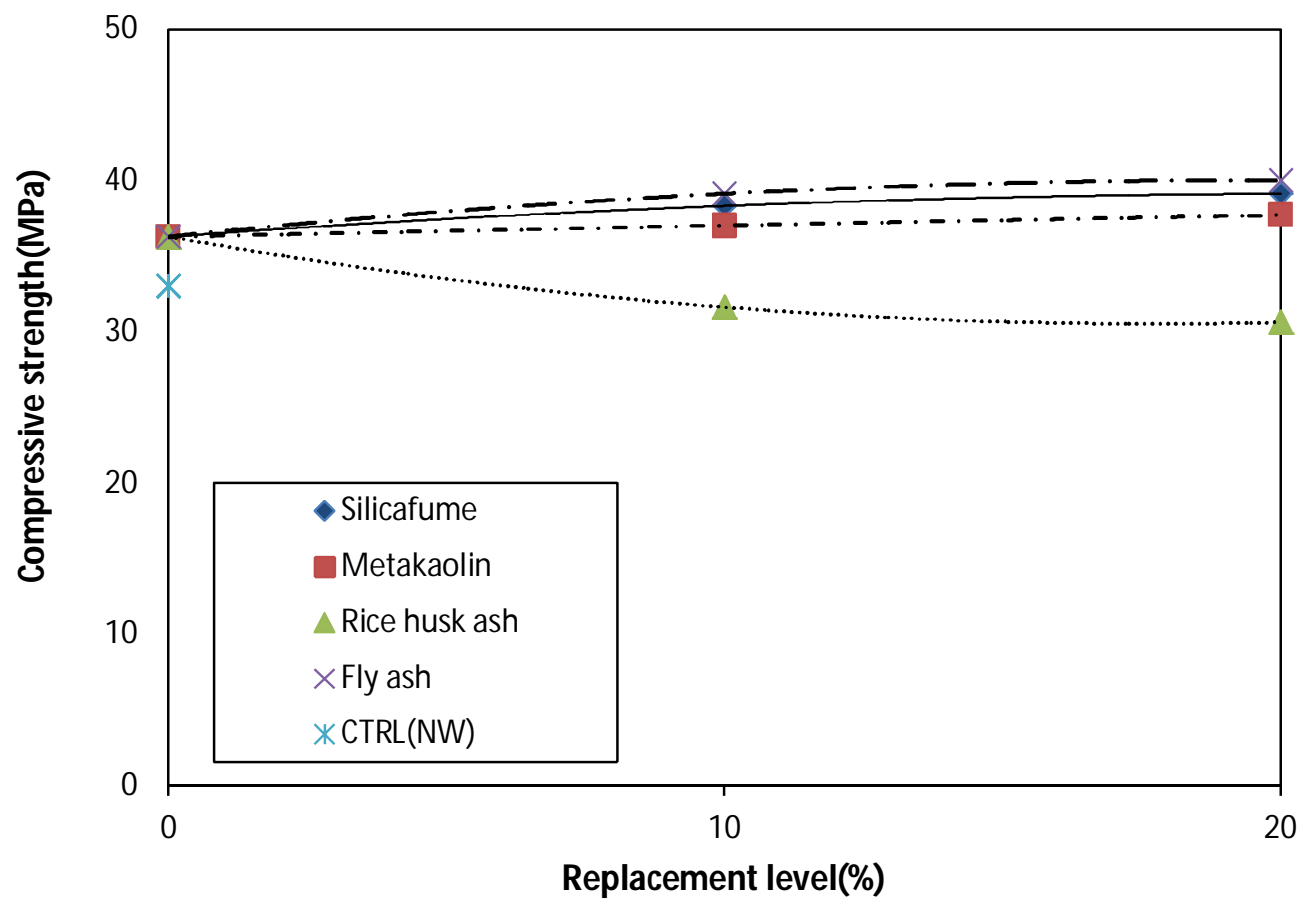

Fig. 7 Compressive strength of SCC mixes at 7 days. 


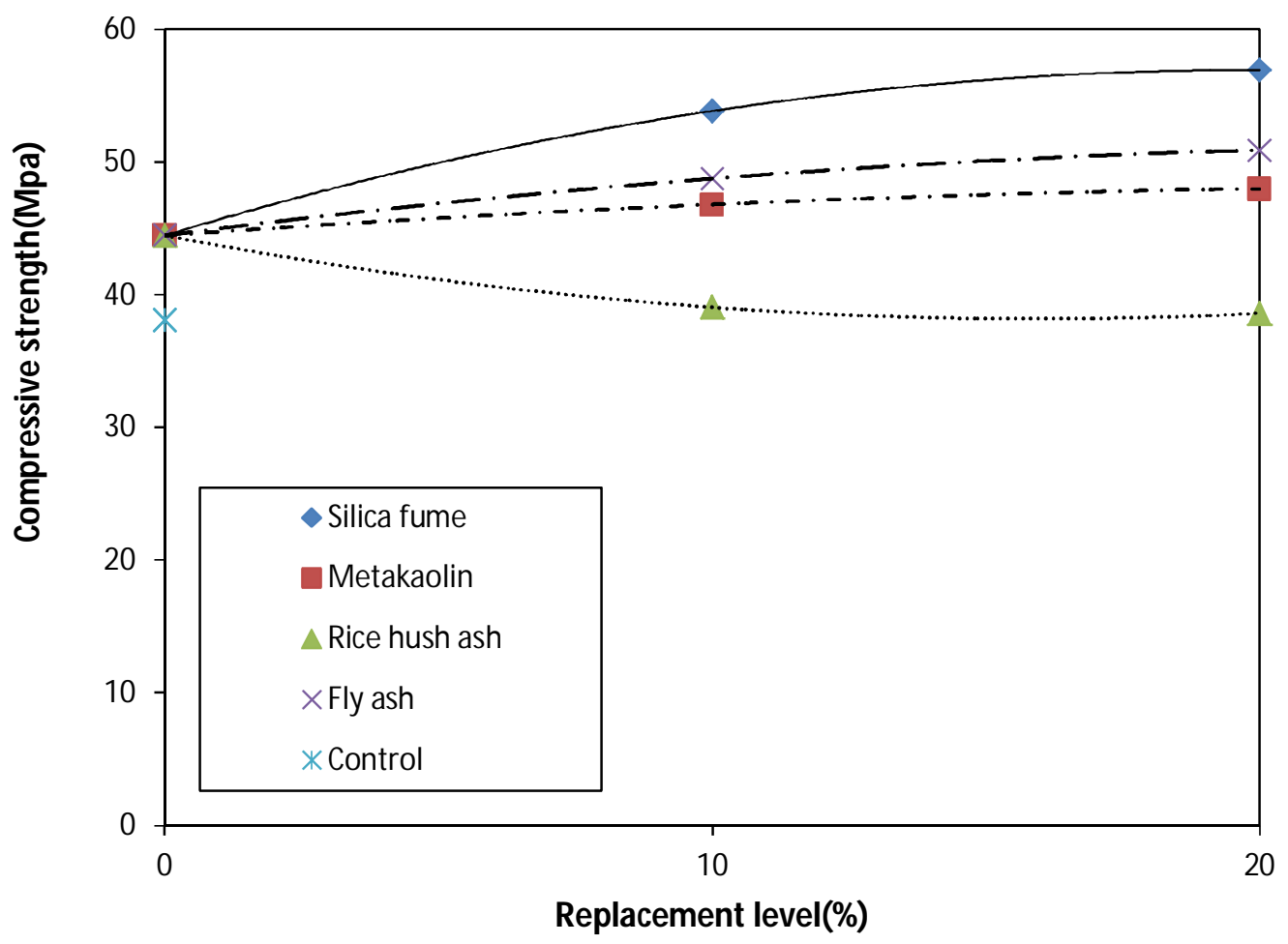

Fig. 8. Compressive strength of SCC mixes at 28 days.

\subsubsection{Splitting tensile strength}

As presented in Fig. 9, the tensile strength of concrete was investigated for SCC mixed with magnetic water and containing $10 \%$ and $20 \%$ SF, MK, RHA and FA using splitting tensile test at the age of 28 days. The tensile strength for SCC with magnetic water and containing $20 \%$ SF, MK, FA and RHA, at the age of 28 days, increased up to $41 \%, 28 \%$, $17 \%$ and $-7 \%$, respectively, more than that for SCC control mixes made with tap water. As displayed in Fig. 9, the enhancement of tensile strength of all concrete mixes varied from 2.8 to 4.2 MPa. Similar to compressive strength test results, the tensile strength of SCC mixes contaning SF and RHA achieved the highest and lowest points, respectively. As given in Fig. 10, the equation of $\mathrm{f}_{\mathrm{t}}=0.11\left(\mathrm{f}_{\mathrm{cy}}\right)^{0.95}$ has been offered as the relationship between the 
compressive strength and splitting tensile strength at the age of 28 days where high correlation coefficient of $\mathrm{R}^{2}=0.79$ were obtained. The results obtained by this equation are very close to values predicted by CEB-FIP [34] and ACI 318-05 [35]. Meanwhile, as suggested by Domone [36], the cube compressive strength was converted to cylindrical strength by applying suitable conversion factor.

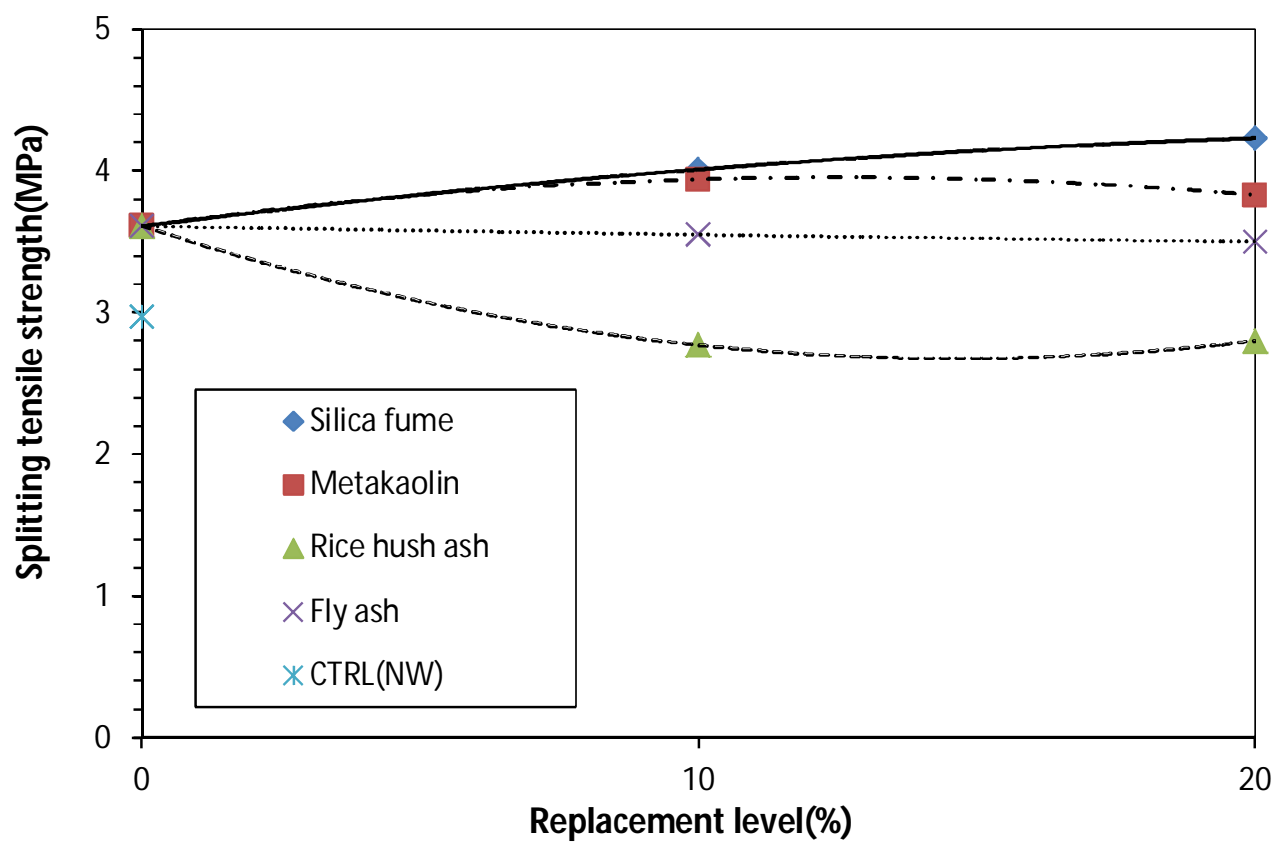

Fig. 9. Splitting tensile strength of SCC mixes at 28 days. 


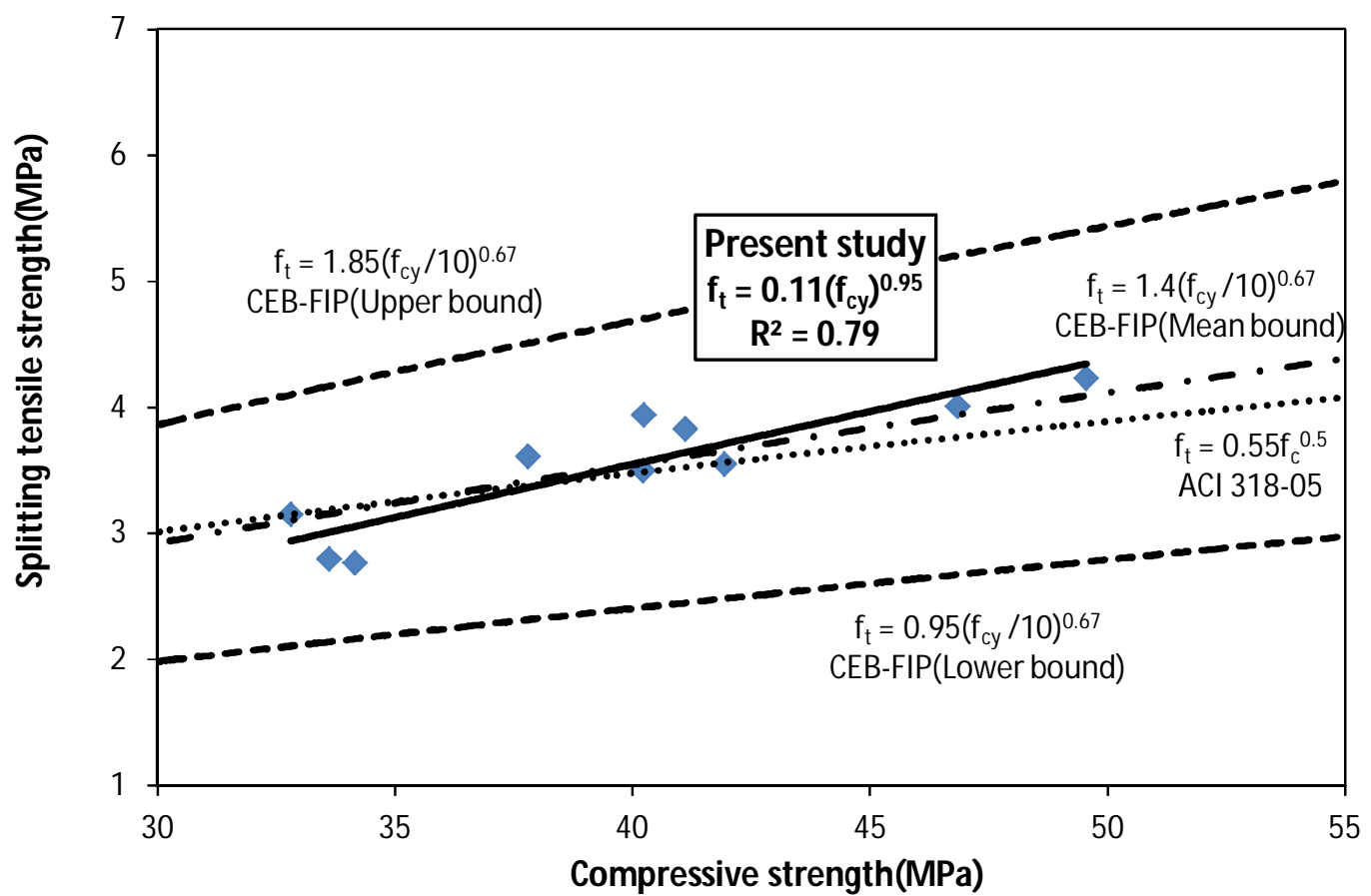

Fig. 10. Variation of splitting tensile strength vs. compressive strength.

\subsubsection{Water absorption}


The results of water absorption on concrete durability for all mixes at the age of 28 days are presented in Fig. 11. Water absorption values of 5\% and above, 3-5\% and 0-3\% were classified as poor, average and good by CEB-FIP [34], respectively. By considering this matter, all concrete mixes can be classified as "good" and "average" concrete quality. The water absorption for all mixes were ranging from $1.9 \%$ to $4.2 \%$ where the highest and lowest points were obtained for SCC control mix made with tap water and SCC containing magnetic water and SF, respectively. For instance, at replacement level of $20 \% \mathrm{SF}$, the water absorption value of SCC decreased up to $50 \%$ and $55 \%$ compared to SCC control mixes made with magnetic and tap water, respectively, because of the alkali-silica reaction in concrete, which could lead to reducing the size of pores in cement paste, as mentioned by Sabet et al. [11].

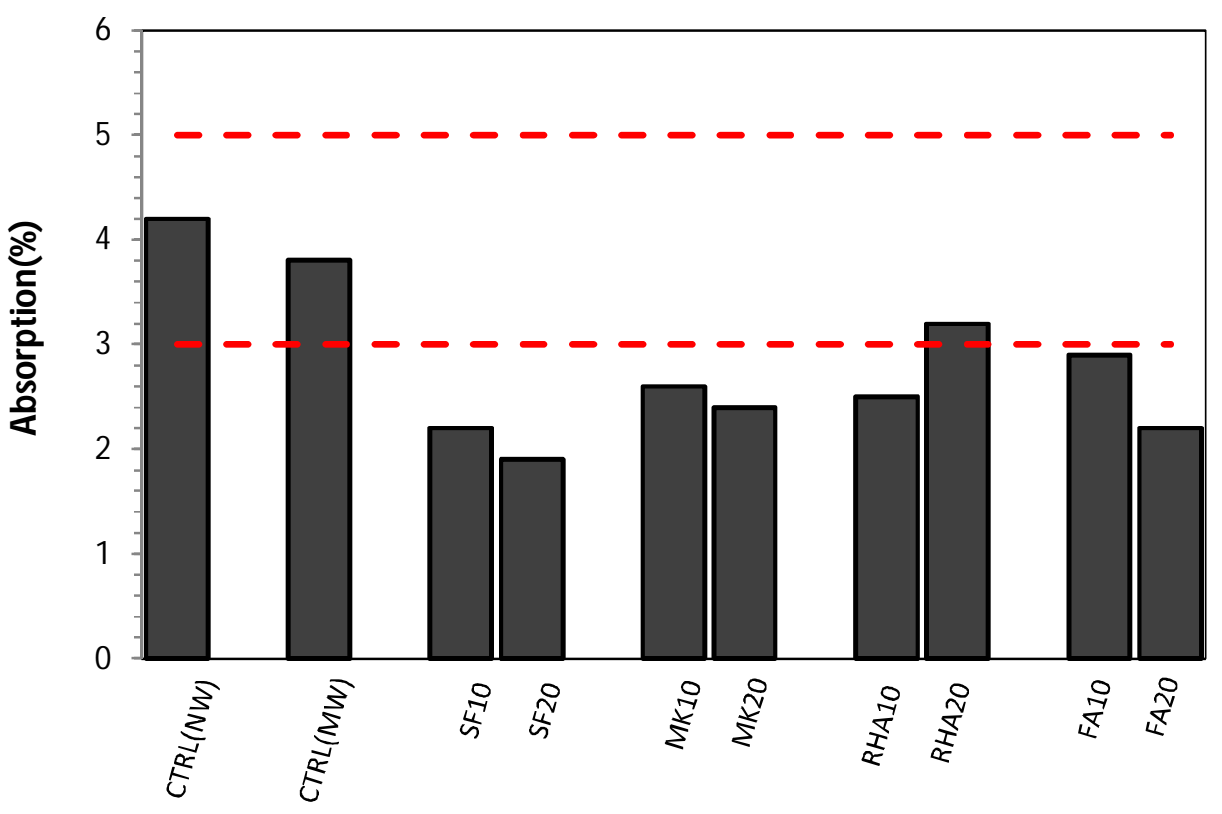

Fig. 11. Water absorption of SCC mixes at 28 days. 


\section{Conclusions}

In this paper, SCC mixed with magnetic water and containing SF, MK, RHA and FA at $10 \%$ and $20 \%$ replacement levels were investigated experimentally. The following conclusions can be drawn from this investigation:

- Magnetic water decreased need for HRWR up to $45 \%$. In addition, all pozzolanic materials except FA increased need for HRWR compared to SCC control mix made with magnetic water.

- All pozzolanic materials in SCC satisfied slump flow properties with accordance to EFNARC limitations and they can improve the self-compatibility criteria in terms of flowability and viscosity.

- Magnetic water causes a decrease in viscosity of SCC mixes in V-funnel and $\mathrm{T}_{50}$ tests. Conversely, SCC incorporating different replacement levels of pozzolanic materials except FA can attain higher viscosity in these tests.

- Magnetic water can improve passing ability of SCC mixes in L-box test, but it can be reduced with different replacement levels of pozzolanic materials except FA.

- The highest 7-day compressive strength of test samples was obtained for SCC incorporating $20 \%$ FA where it increased $21 \%$ compared to that for SCC control mix made with tap water, while with the inclusion of $20 \%$ SF, 28-day compressive strength achieved the highest point with $49 \%$. 
- Of all mixes, SCC containing magnetic water and 20\% SF achieved the highest 28day tensile strength with $41 \%$ compared to SCC control mix made with tap water.

- Magnetic water can decrease water absorption of SCC up to $10 \%$ compared to SCC control mix made with tap water. Furthermore, this value can be reduced up to $55 \%$ for SCC containing $20 \%$ SF and magnetic water.

\section{References:}

[1] H. Okamura, M. Ouchi, Self-Compacting Concrete. J. Adv. Concr. Technol. 1(1)(2003) 5-15.

[2] S. Singh, S. Naval, Effect of magnetic water on the engineering properties of self compacting concrete using binary and ternary blends, Int. J. Sci. Managment. and Technol. 9 (1)(2016).

[3] Z.J. Chau, The new construction method of concrete, The Publishing House of Chinese Architectural Industry, (1996) 401-407.

[4] W. Fu, Z.B. Wang, The new technology of concrete engineering, The Publishing House of Chinese Architectural Industry. (1994) 56-59.

[5] H. Afshin, M. Gholizadeh, N. Khorshidi, Improving mechanical properties of high strength concrete by magnetic water technology, J. Sci. Iranica Trans. A 17(1) (2010) 74-79.

[6] A. Oner, S. Akyuz, An experimental study on optimum usage of GGBS for the compressive strength of concrete, Cem. Concr. Compos. 29(6)(2007) 505-514.

[7] E.H. Yang, Y. Yang, V.C. Li, Use of high volumes of fly ash to improve ECC mechanical properties and material greenness, ACI Mater. J. 104(6)(2007) 620-628. 
[8] M. Gesoglu, E. Guneyisi, E. Ozbay, Properties of self-compacting concretes made with binary. ternary, and quaternary cementitious blends of fly ash, blast furnace slag, and silica fume, Constr. Build. Mater. 23(5) (2009) 1847-1854.

[9] A. Elahi, P.A.M. Basheer, S.V. Nanukuttan, Q.U.Z. Khan, Mechanical and durability properties of high performance concretes containing supplementary cementitious materials, Constr. Build. Mater. 24(3)(2010) 292-299.

[10] M. Jalal, E. Mansouri, M. Sharifipour, AR. Pouladkhan, Mechanical, rheological, durability and microstructural properties of high performance self-compacting concrete containing $\mathrm{SiO}_{2}$ micro and nanoparticles. Mater. Des. 34(2012) 389-400.

[11] F. Sabet, N.A. Libre, M. Shekarchi, Mechanical and durability properties of self consolidating high performance concrete incorporating natural zeolite, silica fume and fly ash, Constr. Build. Mater. 44 (2013) 175-184.

[12] M. Jalal, A. Pouladkhan, O.F. Harandi, D. Jafari, Comparative study on effects of Class F fly ash, nano silica and silica fume on properties of high performance self-compacting concrete, Constr. Build. Mater. 94 (2015) 90-104.

[13] H.Y. Leung, J. Kim, A. Nadeem, J. Jaganathan, M.P. Anwar, Sorptivity of self-compacting concrete containing fly ash and silica fume, Constr. Build. Mater. 113 (2016) 369-75.

[14] M. Jalal, A.A. Ramezanianpour, M.K. Pool, Split tensile strength of binary blended Selfcompacting concrete containing low volume fly ash and $\mathrm{Tio}_{2}$ nanoparticles, Compos. Eng. 55 (2013) 324-337. 
[15] H. Zhao, W. Sun, X. Wu, B. Gao, The properties of the self-compacting concrete with fly ash and ground granulated blast furnace slag mineral admixtures, Journal of Cleaner Production, 15 (2015) 66-74.

[16] C.S. Poon, L. Lam, S.C. Kou, Y.L. Wong, R. Wong, Rate of pozzolanic reaction of metakaolin in high-performance cement pastes, Cem. Concr. Res. 31(9) (2001) 1301-1306.

[17] A.A.A. Hassan, M. Lachemi, K.M.A. Hossain, Effect of Metakaolin and silica fume on the durability of self-consolidating concrete, Cem. Concr. Compos. 34 (6) (2012) 801-807.

[18] S. Dadsetan, J. Bai, Mechanical and microstructural properties of self-compacting concrete, blended with metakaolin, ground granulated blast-furnace slag and fly ash, Constr. Build. Mater. 146 (2017) 658-67.

[19] R. Madandoust, M.M. Ranjbar, H.A. Moghadam, S.Y. Mousavi, Mechanical properties and durability assessment of rice husk ash concrete, Biosys. Eng. 110 (2011) 144-152.

[20] H.T. Le, H.M. Ludwig, Effect of rice husk ash and other mineral admixtures on properties of self-compacting high performance concrete, Mater. Des. 89(2016) 156-66.

[21] N. Su, C.-F. Wu, Mar, Effect of magnetic field treated water on mortar and concrete containing fly ash, Cem. Concr. Compos. 25(7)(2003) 681-688.

[22] N. Su, Y.H. Wu, C.Y. Mar, Effect of Magnetic Water on The Engineering Properties of Concrete Containing Granulated Blast Furnace Slag, Cem. Concr. Res. 30 (4)(2000)599 - 605.

[23] S. Bhatath, S. Subraja, P. Arun Kumar, Influence of magnetized water on concrete by replacing cement partially with copper slag, Journal of Chemical and Pharmaceutical Sciences, 9 (4) (2016). 
[24] A. Ghods, A survey on the mechanical properties of magnetic self-compacting concrete containing nanosilica, International Research Journal of Applied and Basic Sciences, 8 (4) (2014) 413-418.

[25] EFNARC, The European Guidelines for Self-compacting concrete; specification production and use, May 2005.

[26] ASTM C494, Standard Specification for Chemical Admixtures for Concrete, Annual Book of ASTM Standards, American Society for Testing and Materials, West Conshohocken; Pa, USA, 2004.

[27] K.H. Khayat, J. Bickley, M. Lessard, Performance of self-consolidating concrete for casting basement and foundation walls, ACI Mater. J. 97(2000) 374-380.

[28] ASTM C469, Standard Test Method for Splitting Tensile Strength of Cylindrical Concrete Specimens, Annual Book of ASTM Standards, American Society for Testing and Materials, West Conshohocken; Pa, USA, 2002.

[29] ASTM C39, Standard Test Method for Compressive Strength of Cylindrical Concrete Specimens, Annual Book of ASTM Standards, American Society for Testing and Materials, West Conshohocken; Pa, USA, 2003.

[30] ASTM C642, Standard Test Method for Density, Absorption, and Voids in Hardened Concrete, Annual Book of ASTM Standards, American Society for Testing and Materials, West Conshohocken; Pa, USA, 2006.

[31] M.d. Safiuddin, J.S. West, K.A. Soudki, Flowing ability of self-consolidating concrete and its binder paste and mortar components incorporating rice husk ash, Canadian J. Civil Eng. 37(3) (2010) 401-412. 
[32] R. Madandoust, S.Y. Mousavi, Fresh and hardened properties of self-compacting concrete containing metakaolin, Constr. Build. Mater. 35 (2012) 752-760.

[33] M.-H. Zhang, V.M. Malhotra, High-performance concrete incorporating rice husk ash as a supplementary cementing material, ACI Materials Journal, 93(6)( 1996) 629-36.

[34] CEB-FIP, Diagnosis and Assessment of Concrete Structures, state of the art report, CEB Bull.192 (1989)83-85.

[35] ACI318-05, Building Code Requirements for Reinforced Concrete and Commentary (ACI318R-05), American Concrete Institute, Farmington Hills; MI, USA, 2005.

[36] P.L. Domone, A review of the hardened mechanical properties of self-compacting concrete, Cem. Concr. Compos. 29(1)(2007) 1-12. 